\title{
Heroin prescription: a limited but valuable role ${ }^{\dagger}$
}

Luty (2005, this issue) performs a valuable service by directing attention to the new guidelines from the National Treatment Agency. He explains clearly why he thinks these guidelines are wrong. I was a member of the expert advisory group that produced the guidelines, and will therefore attempt to defend them (my arguments do not necessarily reflect the views of all members of the group).

Oral maintenance is the gold standard treatment for people who are established opiate users, whether with methadone or buprenorphine. There is strong evidence for its effectiveness in retaining patients in treatment, reducing illicit opioid use and imprisonment, and preventing HIV infection (Ward et al, 1998). Counselling, detoxification, rehabilitation, occupational advice and housing support must all be available as well, but still in many districts they are not, and moreover often methadone itself is prescribed at inadequate dosage levels.

The Dutch study (van den Brink et al, 2002) of heroin $v$. methadone treatment showed that a significant proportion of 'treatment failures' responded well even if the person was assigned to the methadone arm of the trial, suggesting that the prior failure had been due to inadequate delivery rather than the treatment itself. For all these reasons we recommended that heroin should only be prescribed in line with the eight principles recorded by Luty. The first priority for purchasers must be to ensure that standard treatments are delivered effectively, and with short waiting times.

Nonetheless, even with best treatment, there remain patients whose condition continues to deteriorate. Some have tried methadone and found that they did not like its properties, or that it did not work for them. Some were unable or unwilling to give up injecting. The Swiss health system already offered high-quality treatment for dependent heroin users but still many were not in contact with drug services or had tried them and failed. It was this observation that led to the heroin trials reported by Uchtenhagen et al (1999). In their cohort of 800 participants receiving heroin treatment, there were significant reductions in illicit drug use and criminal behaviour, and improvements in physical and psychological health and in social functioning. Criminal behaviour declined, with the proportion reporting income from illicit sources reducing from $69 \%$ to $10 \%$. Police records and official crime statistics verified self-reported criminal activity. Health improvements included general and nutritional status, and a decline in injection-related skin diseases. It is certainly true that injecting drugs is bad for health, but less so if users receive clean equipment and pharmaceutical heroin.

A World Health Organization report (Ali et al, 1999) confirmed that heroin treatment was feasible, but queried whether improvement was due to heroin or to the psychosocial impact of attending a clinic three times a day. One response is that it would be hard to imagine these patients attending a clinic three times a day if heroin were not available. It is an acknowledged benefit of methadone substitution therapy that it retains people in treatment and brings them into contact with psychosocial support and advice. If heroin is able to perform this function when methadone fails, it is surely an argument in favour rather than against.

Another response is to consider the evidence of the recently completed Dutch trials, in which patients taking heroin and methadone were compared with those prescribed heroin alone (van den Brink et al, 2002). Unlike the study in Switzerland, an adequate control group was retained. These trials recruited 'chronic, treatmentresistant heroin addicts' (van den Brink et al, 2002). The primary outcome measure was a $40 \%$ improvement in physical health, mental health and social functioning. Patients with this outcome were called 'responders'. After 12 months, $48 \%$ of patients in the inhaled heroin group were responders compared with $25 \%$ in the methadone group. Similarly, $57 \%$ of patients in the injected heroin group were responders compared with $32 \%$ in the methadone group. Two months after discontinuation of treatment, the majority of 'responders' had deteriorated considerably. In other words, patients also acted as their own controls. Heroin treatment led to improvements, which dissipated when the treatment was removed.

There is therefore growing evidence that heroin is effective in treatment-resistant cases. The remit of the expert group was to advise on best treatment regardless of cost. We judged that treatment with injectable methadone and heroin was not a first-line treatment, but should be provided when other treatments fail. This would certainly be expensive, but in fact there is enough money in the system to fund comprehensive health care without plundering the National Health Service. A Select Committee report advised that a moderate shift in spending from enforcement to health care would be sufficient (Home Affairs Committee, 2002). In 2001-2 $\mathrm{f3} .5$ billion was spent in England and Wales on the direct and indirect costs of drug misuse, but only $f 217$ million was spent on treatment, less even than on drug-related court cases alone (Audit Commission, 2002). Moreover, treatment can actually save money. In the UK treatment is calculated to save $\mathrm{f} 3$ for every $\mathrm{f} 1$ spent (Gossop et al, 1998). The heroin trials in Switzerland saved $f 7000$ per patient per year, even when their expensive system of supervision was taken into account (Uchtenhagen et al, 1999).

Would this work in England? The recommended model is a compromise between highly regimented continental European protocols and our current relatively lax approach. The group accepted that full supervision is needed at first, up to three times daily (because heroin needs to be injected three times daily). Such supervision 
would prevent diversion, encourage safe injection, facilitate the use of higher dosages and allow the inclusion of patients who are more chaotic. It would also allay the fears of the general public and encourage the confidence of prescribing doctors. One survey showed that lack of access to supervision was a major factor deterring doctors from prescribing heroin (Metrebian et al, 2002). On the other hand, some people become stable on prescribed heroin, wish to move away from drug-taking circles and to look for work or further education, but prove unable to move on to oral medication or abstinence (Stimson \& Ogborne, 1970). For these people, continued full supervision would be countertherapeutic. Moreover, long-term thrice-daily supervision would be impractical for people living many miles from treatment centres. Our public transport is not as good as that in Switzerland.

Only in the UK have doctors been allowed to prescribe heroin in the course of normal treatment. Luty is right to point out that few doctors make use of this privilege, and to argue that perhaps this indicates that the treatment is not very effective. To show why this is not the case requires some knowledge of history, and particularly an understanding of why during the last 30 years heroin has usually been prescribed at sub-

therapeutic dose levels when it has been prescribed at all. We now know from the European research that the therapeutic dosage of heroin is usually $400-600 \mathrm{mg} /$ day (Carnwath \& Merrill, 2002), similar to dosage levels used in the UK until about 1970. At that time doctors were becoming worried that prescribed medication was being diverted and abused. At the beginning of the 1960s there was a sharp increase in the numbers of heroin users. The second Brain Committee was established, and concluded that 'the majority source of supply has been the activity of a very few doctors who have prescribed excessively for addicts' (Ministry of Health \& Scottish Home and Health Department, 1965). It recommended that only psychiatrists working at special drug clinics should prescribe heroin for the treatment of addiction, and that they would in future need Home Office licenses.

Whereas previously doses of heroin had been designed to make patients feel comfortable, a new model of 'competitive prescribing' became established, with doctors competing against the illicit drug market by maintaining heroin users on 'just the right dose'. Too much, and they might sell it; too little, and they might turn to the illicit drug market (Stimson \& Metrebian, 2004). Over the subsequent 10 years prescribed heroin dosages fell to an average of $250 \mathrm{mg} /$ day, but with marked variation between clinics. A few continued to prescribe over $500 \mathrm{mg} /$ day, many prescribed less than $100 \mathrm{mg}$. There was no study concerning which dosage level was best. At the same time there was a move away from heroin to methadone, at first mostly injected but later taken by mouth. Methadone was seen as 'medical treatment', whereas heroin was 'feeding a habit'. Very influential in this change from heroin to methadone was the trial by Hartnoll et al (1980), which Luty reports in detail. This was the only controlled trial of heroin $v$. methadone in the UK, but unfortunately it took place after the average dosage of heroin had fallen to levels at which it was no longer effective. Dosages used in the study were between $40 \mathrm{mg}$ and $80 \mathrm{mg} /$ day. This invalidates the trial's conclusions, but nonetheless this study had a major effect in promoting the shift away from heroin (Berridge \& Thom, 1994), in reducing the dosages of medication prescribed and in prejudicing subsequent generations of doctors against using heroin at all.

Marie Nyswander described how she and Vincent Dole originally developed methadone treatment:

"With heroin and morphine, the dosage increased irregularly. . . and I was writing orders round the clock . . . the patients never got dressed, never had any other goals other than waiting for the next shot" (Courtwright, 1997).

In early 1964, two patients were switched to methadone and their behaviour changed dramatically. They got up, dressed and even began going to night school (Courtwright, 1997). The inventors of methadone treatment had no particular prejudice against prescribing heroin, but in practice found it ineffective. History might have been different had either Hartnoll or Nyswander used larger doses of heroin.

\section{References}

ALI, R., AURIACOMBE, M., CASAS, M., LUTY, J. (2004) New guidelines for et al (1999) Report of the External Panel prescribing injectable heroin in opiate on the Evaluation of the Swiss Scientific addiction. Psychiatric Bulletin, 29, Studies of Medically Prescribed Narcotics to Drug Addicts. Geneva: WHO

AUDIT COMMISSION (2002) Changing

Habits. The Commissioning and Management of Community Drug Treatment Services for Adults. Wetherby: Audit Commission Publications.

BERRIDGE, V. \& THOM, B. (1994) The relationship between research and policy: case studies from the postwar history of drugs and alcohol.

Contemporary Drug Problems, 21 599-629.

CARNWATH, T. \& MERRILL, J. (2002) Dose equivalents in opioid substitution treatment. International Journal of Drug Policy, 13, 445-447.

COURTWRIGHT, D.T. (1997) The prepared mind: Marie Nyswander, methadone maintenance and the metabolic theory of addiction. Addiction, 92, 57-65. $123-125$

METREBIAN, N., STIMSON, G. CARNWATH,T., et al (2002) Survey of doctors prescribing diamorphine to opiate dependent drug users in the United Kingdom. Addiction, 97, 1155-1161.

MINISTRY OF HEALTH \& SCOTTISH HOME AND HEALTH DEPARTMENT (1965) Drug Addiction. Second Report of the Interdepartmental Committee. London: HMSO

STIMSON, G.V. \& METREBIAN, N. (2004) Prescribing Heroin. What is the Evidence? York: Joseph Rowntree Foundation.

STIMSON, G.V. \& OGBORNE, A. C. (1970) Survey of addicts prescribed heroin at London clinics. Lancet, i, 1163-1166.

UCHTENHAGEN, A., DOBLER-MIKOLA, A. STEFFEN, T., et al (1999) Prescription of Narcotics for Heroin Addicts. Main Results of the Swiss National Cohort

GOSSOP, M., MARSDEN, J. \& STEWART, Study. Basel: Karger.

M. (1998) NTORS: Changes in Substance Use, Health and Criminal Behaviour One YearAfter Intake. London: Department of Health.

HARTNOLL, R. L., MITCHESON, M. C., BATTERSBY, A., et al (1980) Evaluation of heroin maintenance in controlled trial. Archives of General Psychiatry, 378, 877-884 VAN DEN BRINK, W., VINCENT, M. HENDRIKS, V. M., et al (2002) Medical Co-Prescription of Heroin: Two Randomized Controlled Trials. Utrecht: Central Committee on theTreatment of Heroin Addicts (www. ccbh.nl).

WARD, I MATTICK, R. P \& HALL W. (1998) Methadone Maintenance and other Opioid Replacement Therapies.

HOMEAFFAIRS COMMITTEE (2002) The Amsterdam: Harwood.

Government's Drug Policy: Is It

Working? House of Commons

HC 318-I. London: Stationery Office.

Tom Carnwath Consultant Psychiatrist, Pierremont Unit, Hollyhurst Road, Darlington DL36HX. E-mail:Thomas.Carnwath@cddps.northy.nhs.uk 